\title{
Screening Divalent Metals for A- and B-Site Dopants in $\mathrm{LaFeO}_{3}$.
}

\author{
Felicity H. Taylor,* John Buckeridge and C. Richard A. Catlow \\ University College London, Kathleen Lonsdale Materials Chemistry, Department of Chemistry, 20 Gordon Street, London, \\ WC1H 0AJ, United Kingdom.
}

\begin{abstract}
Doping $\mathrm{LaFeO}_{3}$, a mixed ionic electronic conductor, can serve to increase its ionic and electronic conductivity, as observed in $\mathrm{La}_{1-\mathrm{x}} \mathrm{Sr}_{\mathrm{x}} \mathrm{Co}_{1-\mathrm{y}} \mathrm{Fe}_{\mathrm{y}} \mathrm{O}_{3-\delta}$ (LSCF), a promising intermediate temperature solid oxide fuel cell (IT-SOFC) cathode material. In this study $a b$ initio methods have been employed to assess the viability of a range of divalent A- and B-site dopants for promoting ionic and electronic conductivity, through calculating solution energies and binding energies to charge compensating species. For the A-site, we find that all alkali earth metals considered promote increased conductivity properties, but strontium and calcium have the lowest solution energies and therefore will be suitable dopants, in full agreement with experiment. Surprisingly we find manganese, which has typically been assumed to dope exclusively on the B-site, to have significant probability, based on energetic considerations, to occupy the A-site and be equally as energetically favourable as the traditional strontium dopant under certain conditions. For the B-site, cobalt and nickel, were found to be suitable dopants, promoting ionic and electronic conductivity, due to the variable oxidation state of transition metals. Magnesium also increases conductivity as a B-site dopant in contrast with the other alkali earth dopants studied, which favour the A-site. By considering two compensation mechanisms, $\mathrm{O}^{2-}$ vacancy and hole compensation, we show both oxygen vacancies and holes will be promoted in the doped system, in agreement with the experimentally observed mixed ionic electronic conducting properties of doped systems, including LSCF.
\end{abstract}

\section{Introduction}

Solid oxide fuel cells (SOFCs) show distinct promise as a clean and renewable alternative to burning fossil fuels. They are efficient, can use a variety of fuels, and have proved to be reliable when operated continuously. ${ }^{(1,2)}$ SOFCs have the standard three main components: a cathode, an electrolyte and an anode. During operation, oxygen is reduced at the cathode site to form $\mathrm{O}^{2-}$ ions which migrate through the electrolyte to the anode where they react with a fuel. ${ }^{(1,3)}$ This conduction of ions is a thermally activated process, hence high operating temperatures are necessary, leading to a number of drawbacks including high cost of materials and short lifetimes. The discovery of novel materials for each component is an active field of research, with the aim of bringing operating temperature down to between 500 and $800^{\circ} \mathrm{C}^{(2)}$

As temperatures are reduced, the rate limiting step becomes the reduction of oxygen on the cathode surface; therefore finding cathode materials that catalyse this reaction at lower temperatures is essential to achieve successful intermediate temperature SOFCs (IT-SOFCs). Mixed ionic electronic conductors (MIECs), such as perovskite $\mathrm{LaFeO}_{3}$, show strong potential as cathode materials as the ionic conductivity serves to increase the area within which the oxygen reduction reaction can take place, increasing the activity of the oxygen reduction reaction at the cathode. In particular, when doped, as in for example $\mathrm{La}_{1}$ ${ }_{x} \mathrm{Sr}_{\mathrm{x}} \mathrm{Co}_{1-\mathrm{y}} \mathrm{Fe}_{\mathrm{y}} \mathrm{O}_{3-\delta}$ (LSCF), high electronic and ionic conductivities have been observed within the intermediate temperature range, along with a high activity towards oxygen reduction. ${ }^{(4-7)}$ Indeed, LSCF-based cathode materials have demonstrated similar power densities to state-of-the-art $\mathrm{La}_{1-\mathrm{x}} \mathrm{Sr}_{\mathrm{x}} \mathrm{MnO}_{3-\delta}$ (LSM) for operating temperatures $100^{\circ} \mathrm{C}$ lower and have a higher tolerance to chromium species, which are often present in common interconnect materials, leading to a more stable performance. ${ }^{(5}$, ${ }^{8)}$ However, degradation is still an issue is these materials, ${ }^{(4,9)}$ although it is proposed that altering their composition could prevent degradation and improve long term stability. ${ }^{(9)}$ With this in mind, understanding doping in the parent material is of primary importance in order to propose design strategies, an area in which computational studies can provide critical insight. ${ }^{(10-}$ 16)

Doping $\mathrm{LaFeO}_{3}$ affects its structural, transport and electrical properties. ${ }^{(17-30)}$ Doping the A-site with divalent metals, in particular the alkali earths, has been shown to increase the oxygen vacancy concentration, and therefore oxide ion conductivity. ${ }^{(17,18,19)}$ While doping on the B-site, for which the focus is first row transition metals, has been shown to affect magnetic properties and electrical conductivity. ${ }^{(17,20,21,22)}$ However there is no consensus on the most appropriate dopant to use for each site. For example, Ortiz-Vitoriano et al. ${ }^{(23)}$ suggest $\mathrm{Ca}$ is the optimum A-site dopant of the alkali earth metals, as it has comparable properties to the strontium doped system while being cheaper, whereas Bidrawn et al. ${ }^{(19)}$ report calcium doped La$\mathrm{FeO}_{3}$ to have a lower ionic conductivity compared to strontium doped $\mathrm{LaFeO}_{3}$ along with a higher activation energy for ionic transport.

Computational studies on doped $\mathrm{LaFeO}_{3}$ are limited and tend to focus on dopant concentration without first considering the most appropriate dopant for this system. ${ }^{(18,31)}$ Work that has examined a range of dopants has generally been carried out using interatomic potential based methods. ${ }^{(32)}$ However, using these approaches to model transition metal ions accurately can pose challenges especially when considering both electronic and point defect compensation of the effective charge of the dopant.

In this paper, a range of divalent dopants in $\mathrm{LaFeO}_{3}$, on the A- and B-site have been investigated using density functional theory (DFT) in order to establish the most appropriate dopant for each site. Manganese, cobalt, nickel and copper are considered for both the A- and B-sites, while magnesium, calcium, strontium, barium and iron are also considered for the A-site; 
the only alkali earth metal considered for the B-site is magnesium. Although we would not expect the transition metals to substitute on the A-site of this material, due to their small ionic radii, they have been included in this work for completeness and to investigate the possibility of these impurities occupying both sites when incorporated in $\mathrm{LaFeO}_{3}$. Solution energies have been calculated, along with the binding energies of these dopants to oxygen vacancies and holes. For the A-site, $\mathrm{Sr}^{2+}$ and $\mathrm{Mn}^{2+}$ are calculated to be the most energetically favourable from each group of dopants, whereas $\mathrm{Co}^{2+}, \mathrm{Ni}^{2+}$ and $\mathrm{Mg}^{2+}$ are the most favourable B-site dopants, from the range of divalent metals studied.

\section{Simulation Methods}

The ambient temperature structure of $\mathrm{LaFeO}_{3}$ is the orthorhombic perovskite form, Pbnm no. 62, ${ }^{(33)}$ shown in Figure 1, and has been adopted throughout our investigation. Calculations were carried out using ab initio based methods, as outlined below.

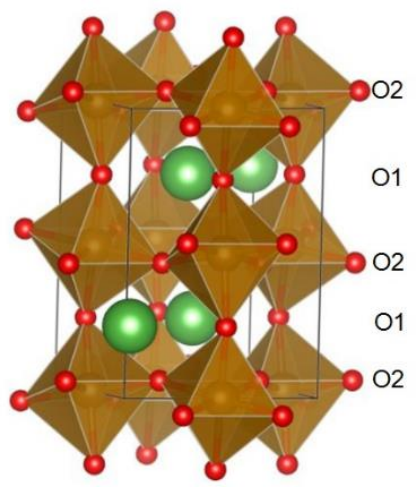

Figure 1. Orthorhombic form of $\mathrm{LaFeO}_{3}$; lanthanum are shown in green, iron in gold and oxygen in red. The two oxygen environments; $\mathrm{O} 1$ and $\mathrm{O} 2$ are shown to the right of the structure.

All electronic structure calculations were performed, as in ref. [34], using spin-polarised Kohn-Sham DFT $^{(35,36)}$ and $\mathrm{DFT}+\mathrm{U}^{(37)}$ using the plane-wave pseudopotential technique with the projector augmented-wave ${ }^{(38)}$ (PAW) approach to model the core-valence electron interaction, as implemented in the Vienna $a b$ initio simulation package (VASP). ${ }^{(39,40,41)}$ The valence configurations used were: $\mathrm{La}\left(5 s^{2} 5 p^{6} 6 s^{2} 5 d^{l}\right), \mathrm{Fe}$ $\left(4 s^{2} 3 d^{8}\right), \mathrm{O}\left(2 s^{2} 2 p^{4}\right)$. The electron exchange and correlation was evaluated within the generalised gradient approximation (GGA+U) using the functional of Perdew, Burke and Ernzerhof (PBE) ${ }^{(42)}$ which was found to reproduce the experimental structure of $\mathrm{LaFeO}_{3}$ most accurately. ${ }^{(34)} \mathrm{A} \mathrm{k}-$ mesh of $(4 \times 4 \times 3)$ generated by the Monkhorst-Pack ${ }^{(43)}$ scheme is used for Brillouin zone sampling for the $\mathrm{LaFeO}_{3}$ unit cell. Integration over the first Brillouin-zone used Gaussian smearing $(\sigma=0.05)$ during structural relaxations. The plane-wave basis set was converged at a kinetic cutoff of $650 \mathrm{eV}$, with the total energy converging to within $0.001 \mathrm{eV}$ per atom. A $\mathrm{U}_{\text {eff }}$ parameter, which represents the difference between the Coulomb (U) and exchange (J) parameters $\left(\mathrm{U}_{\text {eff }}=\mathrm{U}-\mathrm{J}\right)$ is utilised in the DFT+U calculations, in order to model the electron correlation seen in transition metals. ${ }^{(37)} \mathrm{A} \mathrm{U}_{\text {eff }}$ value of $7.0 \mathrm{eV}$ was applied to $\mathrm{Fe}^{3+}$, determined after comparing experimental structure parameters and properties $^{(44,45,46,47,48)}$ to those calculated at increasing values of $\mathrm{U}_{\text {eff. }}{ }^{(34)}$ A $2 \times 2 \times 1$ supercell with antiferromagnetic $\mathrm{G}$ ordering of the $\mathrm{Fe}^{3+}$ ions was used for all calculations. The energies of supercells containing dopants and defects were calculated at the lattice parameters of the relaxed perfect supercell.

For studying A- and B-site transition metal dopants, a $\mathrm{U}_{\text {eff }}$ value of $4.0 \mathrm{eV}$ was used for both $\mathrm{Mn}^{2+}$ and $\mathrm{Co}^{2+}$ and a value of $7.0 \mathrm{eV}$ was used for $\mathrm{Ni}^{2+}$ and $\mathrm{Cu}^{2+}$, these values were evaluated using the method used in ref. [34] to evaluate the $U_{\text {eff }}$ value for $\mathrm{Fe}^{3+}$; comparing experimental parameters of the metal monoxide with those calculated for a range of values of $U_{\text {eff }}$, (see Supporting Information) while also taking into account common values used in the literature; between 4 and $5 \mathrm{eV}$ for $\mathrm{CoO},{ }^{(44,49}$, ${ }^{50)}$ between 5 and $8 \mathrm{eV}$ for $\mathrm{NiO},{ }^{(51-54)} 7 \mathrm{eV}$ for $\mathrm{CuO}^{(55-58)}$ and between 3 and $5 \mathrm{eV}$ for $\mathrm{MnO},{ }^{(53,59-60)}$ when our results showed little structural change between the monoxides at different values of $U_{\text {eff. }}$.

2.1. Calculating Solution Energies using $D F T+U$ : Solution energies of dopants in charge state $q\left(\Delta H_{f}(q)\right)$ were calculated using the following

$$
\begin{aligned}
& \Delta H_{f}(q)=E^{\text {dopant }}-E^{\text {perfect }} \pm \sum n_{x}\left(E_{x}+\mu_{x}\right)+ \\
& q\left(E_{V B M}+E_{F}+\Delta E_{\text {pot }}\right)+q^{2} E_{i c}, \text { (1) }
\end{aligned}
$$

with $E^{\text {dopant }}$ being the total energy of the relaxed supercell, at constant volume, containing the dopant, $E^{\text {perfect }}$ the energy of the relaxed perfect supercell, $n_{x}$ is the number of atoms or ions added or remove from the system, $E_{x}$ is the elemental reference energy, the energy of an element in its standard state e.g. in a pure metal, and $\mu_{x}$ is the chemical potential of the dopant. When $q \neq 0$, the chemical potential of the electrons in the system needs to be taken into account to correct for the imbalance of charge, which is done with $E_{V B M}$, the energy of the valance band maximum (VBM), and $E_{F}$, the Fermi energy defined with respect to the VBM. In addition, $\Delta E_{p o t}$ accounts for the difference between the potential of the perfect supercell and the supercell containing the charged dopant, and $E_{i c}$, a correction to the interaction of charged defects with their periodic image. ${ }^{(61)}$ In this work, $E_{i c}$ has been calculated using the method outlined by Murphy and Hine, ${ }^{(62)}$ as $\mathrm{LaFeO}_{3}$ is orthorhombic and this method takes into account the differences in dielectric tensors along the $\mathrm{a}, \mathrm{b}$ and $\mathrm{c}$ lattice parameters. For $E^{\text {dopant }}$, one dopant in a $2 \times 2 \times 1$ supercell, containing 80 atoms, was used, leading to a doped stoichiometry of $\mathrm{La}_{0.94} \mathrm{M}_{0.06} \mathrm{FeO}_{3}$ for A-site dopants and $\mathrm{LaFe}_{0.94} \mathrm{M}_{0.06} \mathrm{O}_{3}$ for B-site dopants.

The chemical potential, $\mu_{x}$, was varied by changing the elemental reference state from a pure metal to a metal oxide, using the anion poor and anion rich (representing the limits of low and high oxygen partial pressures, $p_{\mathrm{O}_{2}}$ ) equations respectively. Under anion poor (i.e. reducing) conditions the replaced ion, A, precipitates out as a metal, whereas under anion rich (i.e. oxidising) conditions the replaced ion forms an oxide with the excess oxygen. Here standard Kröger-Vink notation ${ }^{(63)}$ has been used (with nickel as an example dopant on the A-site):

$$
\begin{aligned}
& 2 A_{A}^{X}+O_{O}^{X}+2 N i(s) \leftrightarrow 2 N i_{A}^{\prime}+2 A(s)+V_{O}^{\ddot{*}}+\frac{1}{2} O_{2} \\
& \text { (2) } \\
& 2 A_{A}^{X}+O_{O}^{X}+2 N i O \leftrightarrow 2 N i_{A}^{\prime}+V_{O}^{\bullet}+A_{2} O_{3},
\end{aligned}
$$

For anion poor, nickel metal is used as the elemental reference state and for anion rich nickel(II)oxide is used. The above equations use oxygen vacancies, $V_{O}^{\bullet}$, to compensate for the charge imbalance caused when divalent ions replace the trivalent ions on the A- and B-site of $\mathrm{LaFeO}_{3}$. Here two divalent dopants are introduced, $2 N i_{A}^{\prime}$, and the resulting net charge of -2 is balanced with one oxygen vacancy, $V_{\ddot{O}} \cdot$. Another compensation 
mechanism is through the formation of holes, $h^{\bullet}$. This mechanism was also investigated in both anion poor and anion rich conditions, which are represented respectively as follows (again using nickel as a demonstrative example):

$$
\begin{aligned}
& A_{A}^{X}+N i(s) \leftrightarrow N i_{A}^{\prime}+A(s)+h^{\bullet} \\
& A_{A}^{X}+N i O+\frac{1}{4} O_{2} \leftrightarrow N i_{A}^{\prime}+h^{\bullet}+\frac{1}{2} A_{2} O_{3}
\end{aligned}
$$

At ambient temperatures and pressures anion rich represents the more realistic operating conditions for SOFCs.

2.2. Calculating Binding Energies: The extent to which a dopant ion increases the conductivity of $\mathrm{LaFeO}_{3}$ will depend on both its solution energy and the extent to which the dopant binds the charge compensating species produced. Significant binding energies can lead to a decrease in the conductivity as the mobile ions and electrons can be trapped by the dopant. The binding energies to oxygen vacancies and holes were calculated using the following respective equations:

$$
\begin{aligned}
& E_{\text {Bind }}=E_{\text {cluster }}-\left(E_{V_{O}}+2 E_{M_{A}^{\prime}}\right) \\
& E_{\text {Bind }}=E_{\text {cluster }}-\left(E_{\mathrm{h}} \cdot+E_{M_{A}^{\prime}}\right)
\end{aligned}
$$

where $E_{\text {cluster }}$ is the formation energy of the dopant and vacancy or hole cluster, $E_{V_{O}}$ is the formation energy of the isolated oxygen vacancy and $E_{M_{A}^{\prime}}$ is the formation energy of the isolated A- or B-site dopant and $E_{\mathrm{h}}$ is the defect energy of an isolated hole. A negative value indicates that the cluster is more stable than the isolated defects and therefore the dopant will bind to the charge compensating species. As shown in Figure 1, there are two inequivalent oxygen sites in $\mathrm{LaFeO}_{3}$, situated in the axial $(\mathrm{O} 1)$ and equatorial $(\mathrm{O} 2)$ position in the $\mathrm{FeO}_{6}$ octahedra; binding energies to oxygen vacancies in both sites have been calculated.

To calculate the solution energy of dopant-vacancy clusters, the most stable configuration of two dopants and an oxygen vacancy in a $2 \times 2 \times 1 \mathrm{LaFeO}_{3}$ supercell needs to be identified. This was achieved using the Site Occupancy Disorder (SOD) program $^{(64)}$ which identifies all the unique configurations of a given composition. In this study, the most stable configuration of the dopant-vacancy clusters was established in two steps: initial screening of all unique configurations was performed using interatomic potentials, then the resulting ten most stable configurations were relaxed using $\mathrm{DFT}+\mathrm{U}$ and the most favourable configuration was found, which was done first with two dopant ions, without the compensating oxygen vacancy, with the process repeated, to find the most favourable site for the compensating oxygen vacancy, using the doped $\mathrm{LaFeO}_{3}$ supercell. The interatomic potential calculations were performed using the short range potential parameters derived by Cherry et al. ${ }^{(65)}$ for $\mathrm{LaFeO}_{3}$ and Lewis and Catlow (66) for the dopant species with the exception of $\mathrm{Cu}^{2+}$ which was derived by Islam and Winch. ${ }^{(67)}$ These calculations were carried out using the GULP $^{(68)}$ code.

\section{Results}

We will consider the effects of doping the A-site and the Bsite separately, first discussing our results for A-site doping.

3.1. A-site: The solution energies of a range of divalent alkaliearth metal and transition metal dopants on the A-site of La$\mathrm{FeO}_{3}$ have been calculated with both hole and oxygen vacancy compensation investigated, using equations 1 to 5, as described above. The results are shown in Table 1 in comparison with the experimental metal-oxygen bond distance in the associated bi- nary oxide, ${ }^{(69-75)}$ a parameter chosen to take into account the effect of Jahn-Teller distortions on the octahedra for copper, which is not represented by ionic radii.

Table 1. The solution energies of divalent alkali-earth metal and transition metal A-site dopants', in anion poor and anion rich conditions, using either hole $\left(h^{\circ}\right)$ or oxygen

\begin{tabular}{|c|c|c|c|c|c|}
\hline \multirow{3}{*}{ M } & \multirow{3}{*}{$\mathrm{M}-\mathrm{O} / \AA^{\mathrm{a}}$} & \multicolumn{4}{|c|}{ Solution Energy / eV } \\
\hline & & \multicolumn{2}{|c|}{$\mathrm{h}^{\bullet}$} & \multicolumn{2}{|c|}{$\mathrm{V}_{\mathrm{O}} \cdot$} \\
\hline & & Poor & Rich & Poor & Rich \\
\hline \multicolumn{6}{|c|}{ Alkali Earth Metals } \\
\hline $\mathrm{Mg}_{\mathrm{La}}{ }^{\prime}$ & $2.109^{\mathrm{a}}$ & 4.961 & 1.739 & 3.598 & 1.450 \\
\hline CaLa' & $2.406^{\mathrm{b}}$ & 3.316 & 0.587 & 2.501 & 0.682 \\
\hline $\mathrm{Sr}_{\mathrm{La}^{\prime}}$ & $2.580^{\mathrm{c}}$ & 3.306 & 0.079 & 2.494 & 0.343 \\
\hline BaLa' & $2.770^{\mathrm{d}}$ & 3.992 & 0.248 & 2.952 & 0.456 \\
\hline \multicolumn{6}{|c|}{ Transition Metals } \\
\hline $\mathrm{Cu}_{\mathrm{La}}{ }^{\prime}$ & $1.951^{\mathrm{e}}$ & 9.050 & 1.886 & 6.324 & 1.548 \\
\hline $\mathrm{Ni}_{\mathrm{La}}{ }^{\prime}$ & $2.089^{\mathrm{a}}$ & 7.762 & 2.110 & 5.465 & 1.697 \\
\hline Cola' & $2.130^{\mathrm{f}}$ & 7.162 & 1.343 & 5.065 & 1.186 \\
\hline $\mathrm{Fe}_{\mathrm{La}}{ }^{\prime}$ & $2.163^{\mathrm{g}}$ & 5.896 & 1.551 & 4.221 & 1.325 \\
\hline $\mathrm{Mn}_{\mathrm{La}}{ }^{\prime}$ & $2.223^{\mathrm{a}}$ & 6.159 & 1.330 & 4.397 & 1.177 \\
\hline
\end{tabular}
vacancy $\left(\mathrm{V}_{\mathrm{O}}{ }^{*}\right)$ compensation, along with the metal-oxygen bond length in the dopants associated binary oxide; M-O. ${ }^{\mathrm{a}}$ Ref $69^{\mathrm{b}} \operatorname{Ref} 70^{\mathrm{c}} \operatorname{Ref} 71^{\mathrm{d}} \operatorname{Ref} 72^{\mathrm{e}} \operatorname{Ref} 73^{\mathrm{f}} \operatorname{Ref} 74^{\mathrm{g}} \operatorname{Ref} 75$.

For the alkali earth dopants, the solution energies decrease with increasing metal to oxygen (M-O) bond length until barium, for which the solution energy increases. This increase in solution energy is due to divalent barium having a larger ionic radius of $1.42 \AA,{ }^{(76)}$ than that of the trivalent lanthanum ion it has replaced $\left(1.36 \AA^{(76)}\right)$. For the transition metals, the solution energies decrease as the $\mathrm{M}-\mathrm{O}$ bond length increases. For both sets of dopants, the closer their M-O bond length is to the average La-O bond length $(2.596 \AA)$ in this material, the lower is its solution energy. This trend is followed by both compensation mechanisms, as is shown clearly in Figure 2.

For the transition metal dopants we should consider the spin orientation of the dopant. In stoichiometric $\mathrm{LaFeO}_{3}$, the B-site $\mathrm{Fe}^{3+}$ ions are antiferromagnetically ordered which may affect the spin direction of dopants in either the A- or B-site. Therefore, the solution energies of transition metal dopants in both spin up and down orientations, with respect to the c lattice parameter, were calculated and compared. On the A-site, there was no significant difference observed between these solution energies, the largest difference is observed for $\mathrm{Fe}^{2+} ; 0.02 \mathrm{eV}$, suggesting spin does not play a strong role on this site.

Clearly incorporating dopants under anion rich conditions is more favourable for both sets of dopants and both compensation mechanisms, compared to anion poor conditions, which is driven by the formation of the stable $\mathrm{A}_{2} \mathrm{O}_{3}$ product under anion rich conditions. Interestingly, under anion rich conditions, (which are more likely to prevail in many experimental conditions), the difference between the solution energies of the two compensation mechanisms is small indicating that, in doped 
systems formed under these conditions, both holes and oxygen vacancies will be present, demonstrating the mixed ionic electronic properties of doped systems. Of the alkali earth dopants, strontium has the lowest solution energy, under both conditions. However, under anion poor conditions, the solution energies of strontium and calcium are almost identical, while, oxygen vacancy compensation is clearly more favourable; therefore, incorporating dopants under these conditions will serve to increase the ionic, but not the electronic conductivity of the material.
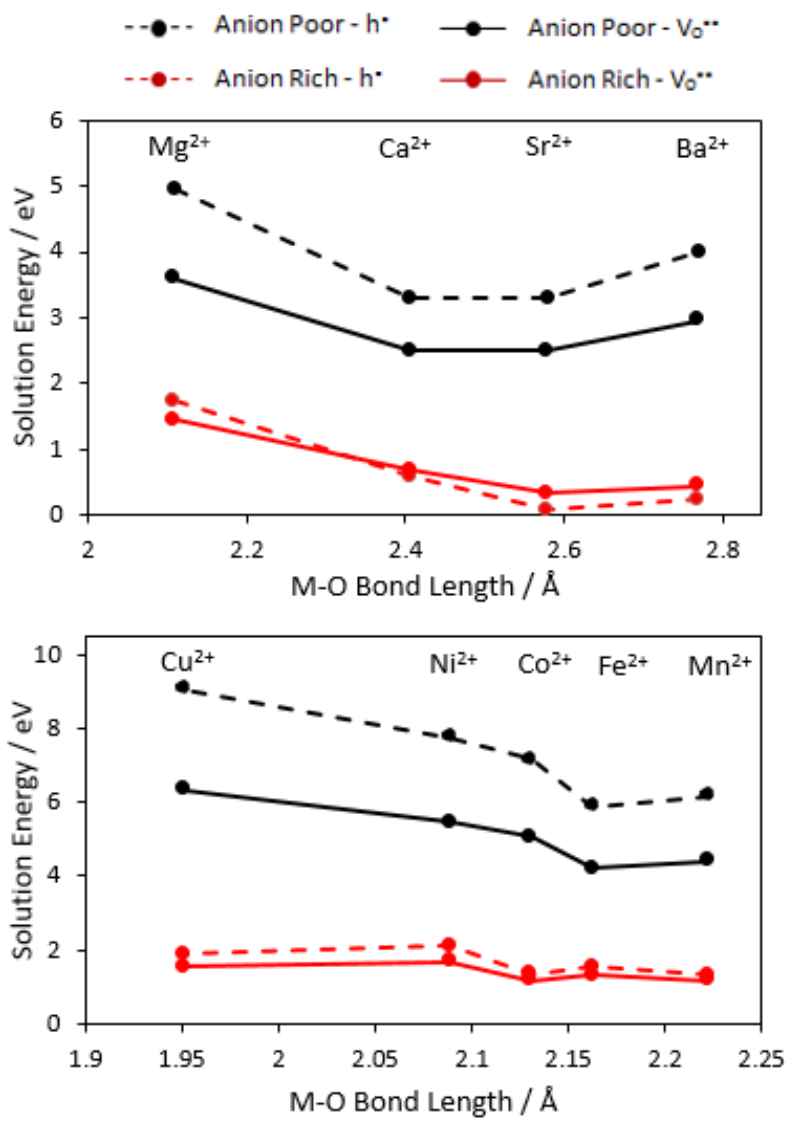

Figure 2. Solution energies of A-site dopants with increasing M-O bond length under anion poor (black) and anion rich (red) conditions; alkali earth metals are on top and transition metals on the bottom, with oxygen vacancy (solid line) and hole (dashed line) compensation.

For the transition metals, manganese has the lowest solution energy, under both anion rich and poor conditions. However, in anion rich conditions, there is only a small difference between the solution energies of all the transition metals studied. As with the alkali earth dopants, there is a significant difference between oxygen vacancy and hole compensation under anion poor conditions, with oxygen vacancies forming in preference, leading to an increase in oxygen vacancy concentration on doping under these conditions, but not holes. Whereas anion rich conditions will promote the formation of both types of compensation.

3.1.1. Hole Localisation: The extent to which a hole localises was determined by comparing the charge densities of the doped and undoped systems. Due to the self-interaction error present in DFT, modelling hole localisation accurately is a challenge and often produces erroneous results. However, in our investigation we found that introducing a hole only affected the oxygen sub lattice in $\mathrm{LaFeO}_{3}$ in a minor way; either by the hole localising on a set of specific oxygen ions, or by delocalising throughout the lattice. As only one sub lattice is involved, the most significant error using GGA+U will be systematic, allowing us to study the trends in hole localisation for each set of dopants. (Distorting oxide ions was found not to promote small polaron formation on those ions).

For the alkali earth metal dopants, when a hole is generated in compensation, the hole tends to delocalise around the lattice, with only slight localisation on the oxygen ions surrounding the dopant. This delocalisation increases from magnesium to strontium, before decreasing for barium. For the transition metals, however, the hole is consistently localised on the nearest neighbour oxygen ions surrounding the dopant from manganese to copper. The delocalisation of the hole in the case of alkali earth doping, (except for magnesium) may account for the hole compensation being slightly more favourable than oxygen vacancy compensation under anion rich conditions for these dopants, whereas the opposite is seen for those dopants that show hole localisation.

The effect of hole localisation on the oxygens surrounding the dopant, for $\mathrm{Mg}$ and $\mathrm{Ba}$, is further demonstrated by the change in metal-oxygen bond lengths caused by the dopant: the greater the difference from the lanthanum-oxygen bond length, the higher the degree of hole localisation (or small polaron formation). For both sets of A-site dopants, where localisation is observed, the hole predominantly localises on the six oxygens that have the shortest La-O bonds in the pure material. The change in bond lengths on doping for these six bonds are shown in Tables 2 and 3 for the alkali earth and the transition metal dopants respectively, a positive number indicates an increase in bond length, whereas a negative value shows a decrease.

Table 2. The difference between bulk $\mathrm{LaFeO}_{3} \mathrm{La}-\mathrm{O}$ bond lengths and the M-O bond lengths in alkali earth doped La$\mathrm{FeO}_{3}$ with hole compensation.

\begin{tabular}{ccccc}
\hline \multirow{2}{*}{ La-O / $\AA$} & \multicolumn{4}{c}{ Difference / $\AA$} \\
& $\mathrm{Mg}-\mathrm{O}$ & $\mathrm{Ca}-\mathrm{O}$ & $\mathrm{Sr}-\mathrm{O}$ & $\mathrm{Ba}-\mathrm{O}$ \\
\hline 2.555 & 1.00 & -0.04 & 0.09 & 0.23 \\
2.659 & 0.83 & 0.01 & 0.08 & 0.16 \\
2.659 & 0.83 & 0.01 & 0.08 & 0.16 \\
2.442 & -0.40 & -0.01 & 0.09 & 0.21 \\
2.442 & -0.40 & -0.01 & 0.09 & 0.21 \\
2.407 & -0.37 & -0.01 & 0.09 & 0.19 \\
\hline
\end{tabular}

For the alkali earth dopants, where hole localisation is only observed in magnesium and barium doped $\mathrm{LaFeO}_{3}$, only these dopants show a notable change in bond length compared to the $\mathrm{La}-\mathrm{O}$ bond. The localisation of the hole adjacent to $\mathrm{Mg}^{2+}$ and $\mathrm{Ba}^{2+}$ is due to the significant difference in ionic radii between these dopants and $\mathrm{La}^{3+}$; the dopants with similar radii; $\mathrm{Sr}^{2+}$ and $\mathrm{Ca}^{2+}$, do not cause hole localisation.

For the transition metal dopants, hole localisation on the surrounding oxygens is observed for all dopants, but to varying degrees. The largest hole density on neighbouring oxygen ions is 
seen on cobalt and copper, which show the largest difference in bond lengths compared to La-O. Another factor that needs considering when discussing hole localisation for transition metal dopants, is the possibility of the hole localising on the dopant itself, due to their variable oxidation states. The extent of hole localisation on the dopant was established by comparing the relaxed magnetic moment of the dopant, in the $2 \times 2 \times 1 \mathrm{LaFeO}_{3}$ supercell, with its expected value as a divalent dopant. The expected values for the transition metal dopants are; 5, 4, 3, 2 and $1 \mu_{\mathrm{B}}$ for $\mathrm{Mn}, \mathrm{Fe}, \mathrm{Co}, \mathrm{Ni}$ and $\mathrm{Cu}$ respectively. The relaxed magnetic moments have been scaled to account for $\mathrm{Fe}^{3+}$, which has $\mathrm{a} \mathrm{d}^{5}$ configuration, having a relaxed magnetic moment of $4.4 \mu_{\mathrm{B}}$ in our supercell. After scaling, the relaxed magnetic moments of the transition metal dopants in an A-site are; 5.1, 4.3, 3.2, 2.1 and $0.85 \mu_{\mathrm{B}}$, in line with those expected for these dopants in their divalent charge state, demonstrating that there is no hole localisation on the transition metal dopants when they occupy the A-site.

Table 3. The difference between bulk $\mathrm{LaFeO}_{3} \mathrm{La}-\mathrm{O}$ bond lengths and the $\mathrm{M-O}$ bond lengths in transition metal doped $\mathrm{LaFeO}_{3}$ with hole compensation.

\begin{tabular}{cccccc}
\hline \multirow{2}{*}{$\mathrm{La}-\mathrm{O} / \AA$} & $\mathrm{Mn}-\mathrm{O}$ & $\mathrm{Fe}-\mathrm{O}$ & $\mathrm{Co}-\mathrm{O}$ & $\mathrm{Ni}-\mathrm{O}$ & $\mathrm{Cu}-\mathrm{O}$ \\
\hline 2.555 & 0.02 & -0.46 & 1.16 & 0.62 & 0.97 \\
2.659 & 0.38 & 0.44 & 0.94 & 0.54 & 0.85 \\
2.659 & 0.35 & 0.44 & 0.94 & 0.54 & 0.73 \\
2.442 & -0.30 & -0.43 & -0.50 & -0.43 & -0.42 \\
2.442 & -0.31 & -0.43 & -0.52 & -0.43 & -0.52 \\
2.407 & -0.27 & -0.45 & -0.54 & -0.40 & -0.42 \\
\hline
\end{tabular}

3.1.2. Binding Energies: The binding energies of these divalent dopants with the two charge compensating species should be considered before choosing the most appropriate dopant. All dopants studied promote both oxygen vacancy and hole formation. However, to effect an increase in conductivity, the dopant must not bind strongly to these species. Tables 4 and 5 show the binding energies for the divalent A-site alkali earth and transition metal dopants respectively.

Table 4. Calculated binding energies of A-site alkali earth dopants with oxygen vacancies and holes in $\mathrm{LaFeO}_{3}$, binding energies for oxygen vacancies in both the 01 and 02 sites have been calculated.

\begin{tabular}{ccccc}
\hline \multirow{2}{*}{ Dopant } & \multicolumn{4}{c}{ Binding Energy/eV } \\
& $\mathrm{Mg}$ & $\mathrm{Ca}$ & $\mathrm{Sr}$ & $\mathrm{Ba}$ \\
\hline $\mathrm{V}_{\mathrm{O} 1}{ }^{*}$ & -0.393 & -0.034 & -0.061 & -0.620 \\
$\mathrm{~V}_{\mathrm{O} 2}{ }^{*}$ & -0.102 & -0.033 & 0.092 & -0.507 \\
$\mathrm{~h}^{\bullet}$ & 0.243 & 0.202 & 0.188 & 0.129 \\
\hline
\end{tabular}

Oxygen vacancies do not bind significantly to either calcium or strontium: the weak binding of calcium, and strontium to $\mathrm{O} 1$ vacancies, will be overcome under SOFC operating conditions
( $k T=0.075 \mathrm{eV}$ at $873 \mathrm{~K}$, the lower limit of intermediate temperature SOFC operating temperatures). However, magnesium and particularly barium have larger binding energies, very probably due to the mismatch in ionic radii of these dopants compared to lanthanum $(0.89,1.61$ and $1.36 \AA$ respectively for $\mathrm{Mg}^{2+}, \mathrm{Ba}^{2+}$ and $\mathrm{La}^{3+}$, as has been observed in related systems. ${ }^{(77)}$ It is of interest that all dopants have a stronger binding to vacant $\mathrm{O} 1$ sites compared to $\mathrm{O} 2$ sites, a promising result as $\mathrm{O} 2$ vacancies form more favourably compared to $\mathrm{O} 1$ vacancies.

The site of the oxygen vacancy in each doped system, which was determined separately for each dopant using $\mathrm{SOD}^{(64)}$, is dependent on the dopant species as well as the type of oxygen vacancy; $\mathrm{O} 1$ or $\mathrm{O} 2$, causing the difference in the binding energies observed for the two sites. For the $\mathrm{O} 1$ site, with the exception of magnesium, the vacancy occupies one of the nearest neighbour oxygen sites to one of the dopants, whereas for the $\mathrm{O} 2$ site, for strontium and barium, the vacancy is in an oxygen site between the two dopants, which distributes the charge from the vacant site between the two dopants, causing a smaller binding energy to either of the positively charged dopants. The exceptions to this are magnesium - for which the $\mathrm{O} 2$ vacancy is located next to only one dopant and the $\mathrm{O} 1$ site is not a nearest neighbour site, but a next nearest neighbour site, and calcium, for which both $\mathrm{O} 1$ and $\mathrm{O} 2$ sites are bonded only to one dopant, which leads to the similarity observed between the binding energies of calcium to the two oxygen vacancy sites.

None of the alkali earth metal dopants studied bind to holes, suggesting these dopants should cause an increase in electrical conductivity in this material, if incorporated under the appropriate conditions. Combining these results with the solution energies calculated suggests that strontium or calcium would be appropriate A-site alkali earth metal dopants, in line with experimental results which show increased ionic conductivity in $\mathrm{Sr}-$ and $\mathrm{Ca}$ - doped $\mathrm{LaFeO}_{3}$ compared to the undoped material, ${ }^{(19,23)}$ as well as an increase in the electronic conductivity,.$^{(78,79,80,81)}$

Table 5. Calculated binding energies of A-site transition metal dopants with oxygen vacancies and holes in $\mathrm{LaFeO}_{3}$, binding energies to oxygen vacancies in both the $\mathrm{O1}$ and $\mathrm{O2}$ sites have been calculated.

\begin{tabular}{cccccc}
\hline \multirow{2}{*}{ Dopant } & \multicolumn{5}{c}{ Binding Energy / eV } \\
& $\mathrm{Cu}$ & $\mathrm{Ni}$ & $\mathrm{Co}$ & $\mathrm{Fe}$ & $\mathrm{Mn}$ \\
\hline $\mathrm{V}_{\mathrm{O} 1}{ }^{*}$ & -0.380 & -0.567 & -0.054 & -0.464 & -0.143 \\
$\mathrm{~V}_{\mathrm{O} 2}{ }^{*}$ & -0.159 & -0.624 & -0.112 & -0.117 & -0.155 \\
$\mathrm{~h}^{\bullet}$ & 0.303 & 0.284 & 0.237 & 0.154 & 0.224 \\
\hline
\end{tabular}

Interestingly, whereas the alkali earth metal dopants bind to $\mathrm{O} 1$ oxygen vacancies stronger than to $\mathrm{O} 2$, the transition metal dopants have a stronger binding to $\mathrm{O} 2$ oxygen vacancies, in the majority of cases, the key exceptions being $\mathrm{Fe}$ and $\mathrm{Cu}$. The binding energy of transition metal dopants to oxygen vacancies generally increase as the $\mathrm{M}-\mathrm{O}$ bond length of the associated binary oxide decreases, except for $\mathrm{Cu}$, which shows a lower binding energy than expected and Fe with an $\mathrm{O} 1$ vacancy, which is significantly higher than expected. The difference for copper can be attributed to the greater stability of $\mathrm{Cu}$ in a square planar geometry compared to the 12-coordinate geometry of lanthanum in $\mathrm{LaFeO}_{3}$. The A-site copper dopant shifts away from the La site into a square planar site between four of the oxygen ions, 
stabilising the dopant and decreasing the magnitude of its binding energy, which can be seen in Figure 3. However, this distortion to the lattice makes it highly unlikely that copper will occupy an A-site in this material, and favours the B-site instead, a point discussed in the next section.

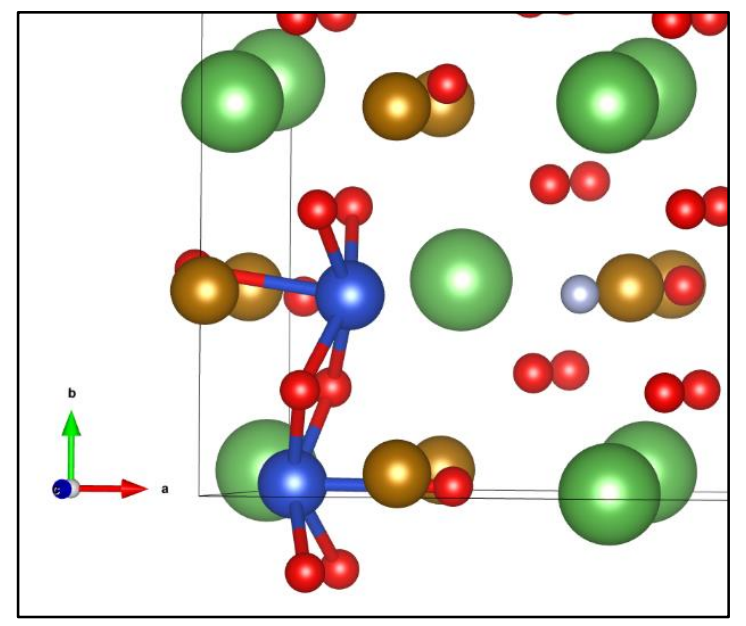

Figure 3. The most stable dopant-vacancy cluster for an A-site copper dopant, showing relaxed position of an A-site copper dopant (blue). The dopant has shifted significantly away from one oxygen ion to form a pseudo-square planar geometry with four of the other oxygen ions. This shift will be more favourable if the oxygen site it is shifting away from is vacant, as is shown here with the oxygen vacancy shown in grey.

The significantly larger binding energy for Fe to an $\mathrm{O} 1$ oxygen can be explained as due to the nucleation of a secondary $\mathrm{Fe}_{2} \mathrm{O}_{3}$ phase within the structure, seen in Figure 4. As the $\mathrm{O} 2$ vacancy is a nearest neighbour to one of the Fe ions it breaks up this secondary phase; therefore, this higher binding energy is only seen for the $\mathrm{O} 1$ vacancy. The tendency of the majority of transition metal dopants to bind to $\mathrm{O} 2$ site vacancies is probably due to the closer proximity of the $\mathrm{O} 2$ site to the lanthanum site compared to $\mathrm{O} 1$.

As with the alkali earth dopants, none of the transition metal dopants studied bind significantly to holes. Combining these results with the calculated solution energies suggests that $\mathrm{Mn}^{2+}$ could be an appropriate A-site dopant, due to its low solution energy and small binding energy.

Although strontium is often used as an A-site dopant for perovskite materials such as $\mathrm{LaFeO}_{3},{ }^{(5,82,83)}$ manganese has previously been assumed to occupy the B-site when used as a dopant, a point that is discussed further in the next section. It would be of interest to investigate the effect of doping the Asite with both strontium and manganese which, according to our results, would lead to a promotion in both of bulk ionic and electronic conductivity in $\mathrm{LaFeO}_{3}$.

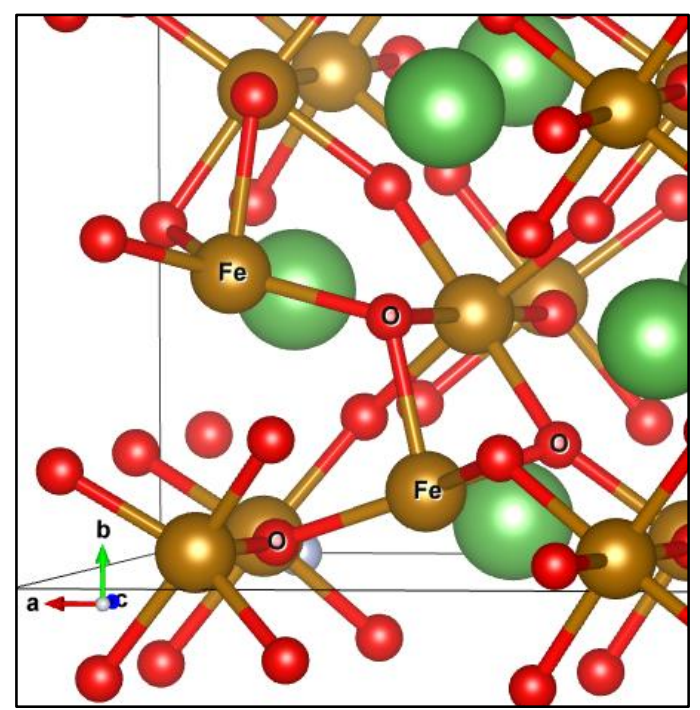

Figure 4. The high binding energy of $\mathrm{Fe}$ to $\mathrm{O} 1$ vacancies indicates incipient nucleation of an $\mathrm{Fe}_{2} \mathrm{O}_{3}$ phase. The A-site Fe dopants are labelled $\mathrm{Fe}$ and the oxygens labelled $\mathrm{O}$ are oxygens with a coordination number of 3 , a feature of the $\mathrm{Fe}_{2} \mathrm{O}_{3}$ lattice. The $\mathrm{O} 1$ vacancy is shown in grey.

3.1.3. Comparison of Site Stability: The promising results displayed by manganese as an A-site dopant leads to the need to establish the likelihood of manganese occupying an A-site compared to a B-site in $\mathrm{LaFeO}_{3}$. The Goldschmidt tolerance factor, $t,{ }^{(84)}$ is a hard sphere model that uses ionic radii to assess the distortion of the lattice caused by a dopant ion. The larger the distortion the less likely the dopant is to occupy that lattice site. It is calculated as follows

$$
t=\frac{r_{x}+r_{A}}{\sqrt{2}\left(r_{x}+r_{B}\right)},
$$

where $r$ is the ionic radii of the ion with A being the A-site cation, $\mathrm{B}$ being the $\mathrm{B}$-site cation and $\mathrm{X}$ being the anion; oxygen in this case. An ideal cubic perovskite would have a Goldschmidt factor of 1 with the lattice becoming more distorted the more the Goldschmidt factor deviates from 1. The Goldschmidt tolerance factor for pure stoichiometric $\mathrm{LaFeO}_{3}$ is 0.908 , for comparison. To calculate the Goldschmidt factor of the doped system, the ionic radius of the divalent dopant was used instead of the ionic radii of $\mathrm{La}^{3+}$ or $\mathrm{Fe}^{3+}$ for A-site and B-site dopants respectively; these are shown in Table 6.

The radius of an ion is highly dependent on the ion's coordination number in the material, with the ionic radius increasing with the coordination. For the transition metals only ionic radii up to a coordination number of 8 are available, so that although the tolerance factor values calculated for the B-site dopants will be accurate - using a coordination number of 6 - those calculated for the A-site will be less so, as the ionic radii associated with a coordination of 8 , or 6 for nickel and copper, rather than the actual value of 12, were used. However, for the A-site, the tolerance factor increases with larger ionic radii. As the ionic radius is expected to increase with a higher coordination number, we expect a higher tolerance factor, and therefore the predicted stability of the perovskite structure will be greater.

It is clear that the majority of the transition metal dopants favour the B-site, causing less distortion compared to when they occupy the A-site, even with the underestimation of the A-site tolerance factors. However, manganese only causes slightly less 
distortion on the B-site compared to the A-site, especially considering this value could be underestimated. This similarity suggests that it may be possible to form $\mathrm{LaFeO}_{3}$ with manganese as an A-site dopant, an interesting avenue of further investigation.

Table 6. The Goldschmit tolerance factor of divalent dopants on the A-site and $\mathrm{B}$-site of $\mathrm{LaFeO}_{3}$.

\begin{tabular}{lcc}
\hline \multirow{2}{*}{ Dopant } & \multicolumn{2}{c}{ Goldschmidt Factor } \\
& A-site & B-site \\
\hline Alkali Earth Metals \\
$\mathrm{Mg}_{\mathrm{Fe}}{ }^{\prime}$ & 0.734 & 0.876 \\
Transition Metals \\
$\mathrm{Cu}_{\mathrm{Fe}}{ }^{\prime}$ & 0.737 & 0.872 \\
$\mathrm{Ni}_{\mathrm{Fe}}{ }^{\prime}$ & 0.722 & 0.889 \\
$\mathrm{CoFe}^{\prime}$ & 0.797 & 0.865 \\
$\mathrm{Fe}_{\mathrm{Fe}}{ }^{\prime}$ & 0.804 & 0.851 \\
$\mathrm{MnFe}^{\prime}$ & 0.818 & 0.832 \\
\hline
\end{tabular}

3.2. B-site: The solution energies of a range of divalent transition metal dopants on the $\mathrm{B}$-site of $\mathrm{LaFeO}_{3}$ have been calculated with both hole and oxygen vacancy compensation. Magnesium, as the smallest alkali earth metal, was also considered as a dopant on the B-site for comparison.

Considering the transition metal dopants initially, we see that, as with the A-site dopants, anion rich provides the most favourable formation conditions for both compensation mechanisms. However, unlike the A-site dopants, the orientation of the spin on the transition metal dopant ion was found to have an impact on the solution energy of the dopants, with lower solution energies if the spin orientation of the dopant is in line with the antiferromagnetic ordering of the $\mathrm{Fe}^{3+}$ ions - a dopant replacing a spin down $\mathrm{Fe}^{3+}$ would favourably be in a spin down orientation.

Table 7. The solution energies of divalent B-site metal dopants in anion poor and anion rich conditions, using either hole $\left(h^{*}\right)$ or oxygen vacancy $\left(\mathrm{V}_{\mathrm{O}^{\circ}}{ }^{*}\right)$ compensation along with the metal-oxygen bond length in the dopants associated binary oxide; M-O. ${ }^{\text {a }}$ Ref $69^{\mathrm{b}}$ Ref 73 'Ref 74

\begin{tabular}{|c|c|c|c|c|c|}
\hline \multirow{3}{*}{ M } & \multirow{3}{*}{$\mathrm{M}-\mathrm{O} / \AA$} & \multicolumn{4}{|c|}{ Solution Energy / eV } \\
\hline & & \multicolumn{2}{|c|}{$\mathrm{h}^{\bullet}$} & \multicolumn{2}{|c|}{ 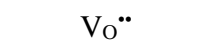 } \\
\hline & & Poor & Rich & Poor & Rich \\
\hline \multicolumn{6}{|c|}{ Alkali Earth Metals } \\
\hline $\mathrm{Mg}_{\mathrm{Fe}}{ }^{\prime}$ & $2.109^{\mathrm{a}}$ & 0.737 & 1.038 & 0.784 & 0.985 \\
\hline \multicolumn{6}{|c|}{ Transition Metals } \\
\hline $\mathrm{Cu}_{\mathrm{Fe}}{ }^{\prime}$ & $1.951^{\mathrm{b}}$ & 4.872 & 1.283 & 3.538 & 1.146 \\
\hline $\mathrm{Ni}_{\mathrm{Fe}}{ }^{\prime}$ & $2.089^{\mathrm{a}}$ & 2.938 & 0.861 & 2.249 & 0.865 \\
\hline $\mathrm{COFe}^{\prime}$ & $2.130^{\mathrm{c}}$ & 2.891 & 0.648 & 2.218 & 0.722 \\
\hline $\mathrm{Mn}_{\mathrm{Fe}}{ }^{\prime}$ & $2.223^{\mathrm{a}}$ & 2.307 & 1.053 & 1.828 & 0.993 \\
\hline
\end{tabular}

Interestingly, different trends are observed for the two conditions investigated. Under anion poor conditions the solution en- ergies decrease with increasing $\mathrm{M}-\mathrm{O}$ bond length. Whereas, under anion rich conditions the solution energies reach a minimum at cobalt and then increase again. As with transition metal dopants on the A-site, there is only a small variation in the solution energies of the dopants studied under anion rich conditions, with the solution energies of dopants with the different compensation mechanisms being comparable so that both holes and oxygen vacancies are likely to be present in B-site doped $\mathrm{LaFeO}_{3}$ formed under this condition. Under anion poor, however, oxygen vacancies are more favourable.

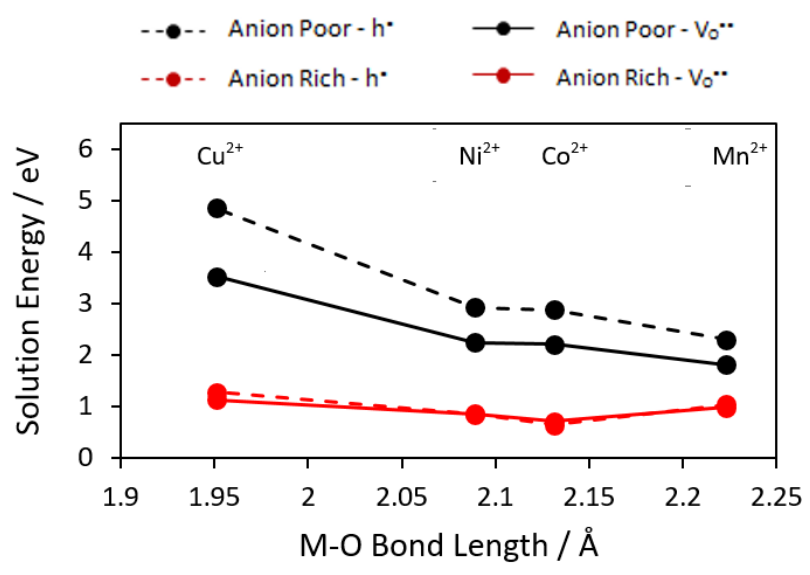

Figure 5. Solution energies of B-site transition metal dopants with increasing $\mathrm{M}-\mathrm{O}$ bond length under anion poor (black) and anion rich (red) conditions. Solution energies are calculated with oxygen vacancy (solid line) and hole compensation (dashed line).

3.2.1. Hole Localisation: As with the A-site dopants, only the oxygen sub lattice is affected when a hole is introduced in compensation, and the self-interaction error in DFT largely cancels. As a consequence, we can analyse the trends in hole localisation observed for these dopants.

Hole localisation with the B-site transition metal dopants follows a similar trend to the A-site alkali earths. Initially, for manganese, the hole is localised on the six surrounding oxygen ions; this localisation decreases from manganese to cobalt, before increasing again for nickel and copper.

The oxidation state of each of the dopants was established via their magnetic moment, following the same method used for the A-site transition metal dopants. It was found that all dopants are in their 2+ charge state, having magnetic moments of; 4.7, 3.0, 1.95 and $0.83 \mu_{\mathrm{B}}$ respectively for $\mathrm{Mn}, \mathrm{Co}, \mathrm{Ni}$ and $\mathrm{Cu}$. Therefore, no localisation is expected on the dopant.

As with the A-site dopants, the hole localisation can be identified by the effect the dopant has on the bond length between the B-site ion and the oxygen ions. The greater the change in bond length caused by the dopant, shown in Table 8, the more localised the hole is on the surrounding oxygens, as the change in bond length is caused by the localised polaron. The largest difference in bond length is seen when manganese is the dopant, and oxygen ions surrounding manganese show the highest degree of localisation. The change in bond length then decreases for cobalt, with almost no change in bond length observed, consistent with no localisation seen on the oxygen ions surrounding 
cobalt. Finally, the change in bond length increases again for $\mathrm{Ni}$ and $\mathrm{Cu}$.

Table 8. The difference between bulk $\mathrm{LaFeO}_{3} \mathrm{Fe}-\mathrm{O}$ bond lengths and the M-O bond lengths in transition metal doped $\mathrm{LaFeO}_{3}$ with hole compensation. Those shown in bold are the bond lengths with oxygen ions that show hole localisation.

\begin{tabular}{ccccc}
\hline \multirow{2}{*}{$\mathrm{Fe}-\mathrm{O} / \AA$} & \multicolumn{4}{c}{ Difference $/ \AA$} \\
& $\mathrm{Mn}-\mathrm{O}$ & $\mathrm{Co}-\mathrm{O}$ & $\mathrm{Ni}-\mathrm{O}$ & $\mathrm{Cu}-\mathrm{O}$ \\
\hline 2.023 & 0.01 & 0.00 & 0.03 & $\mathbf{0 . 0 6}$ \\
2.028 & $\mathbf{0 . 0 9}$ & 0.00 & $\mathbf{0 . 0 4}$ & $\mathbf{0 . 0 3}$ \\
2.018 & $\mathbf{0 . 0 5}$ & 0.01 & $\mathbf{0 . 0 4}$ & -0.02 \\
\hline
\end{tabular}

3.2.2. Binding Energies: The binding energies for the divalent B-site dopants to oxygen vacancies and holes are shown in Table 9.

The results show that all B-site dopants studied bind to both oxygen vacancies and holes. These dopants may therefore decrease the ionic and electronic conductivity of $\mathrm{LaFeO}_{3}$; however the incorporation of B-site dopants could be necessary for the stability of the material and therefore a dopant should be chosen that limits this detrimental effect. Of the transition metals studied, nickel has the lowest binding energy for both oxygen vacancies and holes, although magnesium has lower binding energies to both compensating species. This observation would lead to the conclusion that cobalt, nickel and magnesium would be the good B-site dopants, as they have low solution energies and the minimal binding energies to both oxygen vacancies and holes promoting ionic and electronic conductivity.

Table 9. Calculated binding energies of B-site dopants with oxygen vacancies and holes in $\mathrm{LaFeO}_{3}$.

\begin{tabular}{cccccc}
\hline \multirow{2}{*}{$\mathrm{M}$} & \multicolumn{5}{c}{ Binding Energy/ eV } \\
& $\mathrm{Mg}$ & $\mathrm{Cu}$ & $\mathrm{Ni}$ & $\mathrm{Co}$ & $\mathrm{Mn}$ \\
\hline $\mathrm{V}_{\mathrm{O} 1}{ }^{*}$ & -0.16 & -0.77 & -0.19 & -0.35 & -0.42 \\
$\mathrm{~V}_{\mathrm{O} 2}{ }^{*}$ & -0.17 & -1.40 & -0.20 & -0.42 & -0.40 \\
$\mathrm{~h}^{\bullet}$ & -0.03 & -0.25 & -0.05 & -0.36 & -0.68 \\
\hline
\end{tabular}

Experimentally, promising results have been observed when using cobalt and nickel as B-site dopants. LSCF based materials, as mentioned previously, have high ionic and electronic conductivities, as well as being more resistant to chromium poisoning than other cathode materials. ${ }^{(4,5,7,8)} \mathrm{La}_{\mathrm{x}} \mathrm{Sr}_{1-\mathrm{x}} \mathrm{Fe}_{\mathrm{y}} \mathrm{Ni}_{1-\mathrm{y}} \mathrm{O}_{3-\delta}$ (LSNF) on the other hand, has attracted attention as a cathode material for solid oxide electrolysis cells, the reverse of a solid oxide fuel cells, due to its high electronic conductivity, thermal expansion coefficient similar to that of YSZ, and its high coking tolerance to $\mathrm{CO} .{ }^{(85,86)}$ These first two properties have resulted in $\mathrm{Ni}$-based perovskites also being considered as cathode materials for SOFCs, ${ }^{(87)}$ and our results indicate that they should have ionic and electronic conductivities comparable to LSCF.

These observed properties suggest that the binding energies calculated in this work are not large enough to inhibit conductivity under operating conditions, particularly when A-site dopants are present. There is also evidence that transition metal dopants increase the ionic conductivity without A-site dopants, for example Kharton et al. ${ }^{(88)}$ found doping $\mathrm{LaFeO}_{3}$ with nickel increased the electrical conductivity and bulk ionic conductivity of the material, demonstrating that the binding energies can be overcome.

The results for magnesium as a B-site dopant show promise: it has a lower solution energy than the transition metal dopants and binds less to both oxygen vacancies and holes. In addition, the tolerance factors for magnesium, shown in Table 6 , show that it will cause less strain on the structure of $\mathrm{LaFeO}_{3}$ if situated on the B-site as opposed to the A-site. Therefore magnesium, with its low solution energy and low binding energy to both oxygen vacancies and holes, could be a promising B-site dopant. This has recently been demonstrated experimentally; when comparing $\mathrm{LaFeO}_{3}$ to $\mathrm{LaFe}_{1-\mathrm{x}} \mathrm{Mg}_{\mathrm{x}} \mathrm{O}_{3}(\mathrm{x}=0.05)$ Díez-García and Gómez ${ }^{(89)}$ found that the doped species had a higher efficiency as a photocathode for the oxygen reduction reaction, a key reaction in SOFCs.

The current work has only focused on solution energies and binding energies of these dopants. Other factors will play a role in the suitability of these dopants, including the effect they have on the thermal expansion coefficient (TEC). The effect of nickel and cobalt on the TEC of $\mathrm{LaFeO}_{3}$ is well reported; the presence of cobalt as a dopant causes as increase in the TEC, usually linearly with cobalt content, ${ }^{(90)}$ so low concentrations of cobalt are often used in order to keep the TEC similar to those of common electrolyte material, whereas $\mathrm{Ni}$-doped $\mathrm{LaFeO}_{3}$ materials have favourable TECs, in line with those of common electrolyte materials, even at large concentrations. ${ }^{(91,92)}$ The effect of $\mathrm{Mg}$ on the TEC of $\mathrm{LaFeO}_{3}$ is less well reported, and would need to be investigated before proposing $\mathrm{Mg}$ as a B-site dopant. However, results from $\mathrm{Mg}$ B-site doping of a related compound, $\mathrm{La}_{0.7} \mathrm{Sr}_{0.3} \mathrm{MnO}_{3-\delta}$ are promising, with low TECs and improved electrochemical performance compared to $\mathrm{LaSrMnO}_{3}$ reported. ${ }^{(93)}$

Comparing the solution energies of manganese on both the A-site and the B-site; under anion poor conditions the solution energies of manganese as a B-site dopant are significantly smaller compared to its solution energy as an A site dopant. However, under anion rich conditions, the solution energies are very similar, particularly for oxygen vacancy compensation for which the solution energy of manganese on the B-site is only $0.045 \mathrm{eV}$ lower than that of the A-site.

3.2.3 Variable Oxidation States: Transition metals are able to occupy a variety of oxidation states within a material, a factor which can help or hinder the conductivity properties. With this in mind, we calculated the barrier to oxidation of the appropriate divalent transition metal $\mathrm{B}$-site dopants in $\mathrm{LaFeO}_{3}$. Manganese, cobalt, nickel and copper could form 3+ (or 4+ for manganese) oxidation states within $\mathrm{LaFeO}_{3}$, therefore oxidation to these states was considered.

The barrier to oxidation was calculated based on the following equation, using manganese as an example dopant;

$$
F e_{F e}^{X}+M n_{F e}^{\prime} \leftrightarrow M n_{F e}^{\mathrm{X}}+F e_{F e}^{\prime}
$$

With an addition oxidation step considered for generating manganese 4+

$$
F e_{F e}^{X}+M n_{F e}^{X} \leftrightarrow M n_{F e}^{\cdot}+F e_{F e}^{\prime}
$$

The reaction energies are shown in Table 10.

The calculated energies show that, particularly for manganese, there is a low barrier to oxidising these divalent dopants 
which are therefore likely to be present in $2+, 3+$ and $4+$, for manganese, oxidation states, in agreement with experimental findings. ${ }^{(94)}$ However, nickel, not surprisingly, has a high barrier to oxidation. Interestingly, whereas the other dopants favour high spin configurations, nickel favourably oxidises into the low spin state.

Table 10. The solution energies of transition metal B-site dopants' undergoing oxidation to form 3+ oxidation states and $4+$ in the case of manganese. In all cases the dopants in both $2+, 3+$ and $4+$ states are in high spin states, the value for nickel in brackets represents the oxidation of nickel into a low spin state.

\begin{tabular}{cc}
\hline $\mathrm{M}$ & Solution Energy / eV \\
\hline $\mathrm{Mn}_{\mathrm{Fe}} \mathrm{X}$ & 0.300 \\
$\mathrm{MnFe}_{\mathrm{Fe}}{ }^{\cdot}$ & 0.735 \\
$\mathrm{CoFe}^{\mathrm{X}}$ & 0.860 \\
$\mathrm{NiFe}^{\mathrm{X}}$ & $2.190(1.782)$ \\
$\mathrm{Cu}_{\mathrm{Fe}} \mathrm{X}$ & 1.145 \\
\hline
\end{tabular}

\section{Summary and Conclusion}

The most appropriate A- and B-site dopants were evaluated from a range of divalent transition metals with divalent alkali earth metals also investigated for the A-site. We find for A-site alkali earth metal doping that there is only minimal binding to oxygen vacancies and holes, with the exception of barium which binds strongly to oxygen vacancies in both sites. Low solution energies were calculated for $\mathrm{Ca}^{2+}, \mathrm{Sr}^{2+}$ and $\mathrm{Ba}^{2+}$ under anion rich conditions, with $\mathrm{Sr}^{2+}$ and $\mathrm{Ca}^{2+}$ emerging as the most appropriate due to a combination of low solution energy and minimal binding energies.

For A-site transition metal dopants, the solution energies are all comparable. However, manganese has low binding energies compared to other transition metal A-site dopants, which combined with the minimum distortion of the surrounding $\mathrm{LaFeO}_{3}$ lattice suggests that it would be the most appropriate transition metal A-site dopant in $\mathrm{LaFeO}_{3}$. Comparison with manganese as a B-site dopant showed comparable solution energies under oxygen rich conditions and similar Goldschmidt tolerance factors, suggesting manganese could be a viable A-site dopant, in contrast to its widely assumed B-site position. Cobalt nickel and magnesium were found to be the most favourable B-site dopants, due to low solution energies and low binding energies to oxygen vacancies, along with minimal distortion - particularly for nickel - to the $\mathrm{LaFeO}_{3}$ lattice.

Under anion rich conditions, all dopants, in both sites, demonstrate similar solution energies between the two charge compensation mechanisms investigated; oxygen, vacancies and holes. This result is particularly significant as it explains the origins of the mixed ionic electronic conductivity observed in doped perovskites, such as LSCF, a property that is vital to the application of these materials as cathode materials in intermediate temperature SOFCs.

\section{ASSOCIATED CONTENT}

Supporting Information. U-Values for Metal Oxides.

\section{AUTHOR INFORMATION}

Corresponding Author

* Email: felicity.taylor.14@ucl.ac.uk

\section{Author Contributions}

The manuscript was written through contributions of all authors.

\section{ACKNOWLEDGMENT}

The authors acknowledge funding from the UCL Chemistry Department. We are grateful to Professor Saiful Islam for useful discussions. JB acknowledges funding from the EPSRC project "Energy Materials: Computational Solutions" (EP/K016288/1). The authors also acknowledge the use of the UCL Legion and Grace High Performance Computing Facility (Legion@UCL and Grace@UCL) and the associated support services, and the ARCHER supercomputer through the membership of the United Kingdom's HPC Materials Chemistry Consortium, which is funded by EPSRC Grant No. EP/L000202, in the completion of this work. We acknowledge use of Hartree Centre resources in this work. The STFC Hartree Centre is a research collaboratory in association with IBM providing High Performance Computing platforms funded by the UK's investment in e-Infrastructure.

\section{REFERENCES}

(1) Haile, S. M. Fuel Cell Materials and Components. Acta. Materialia 2003, 51, 5981-6000.

(2) Liu, M.; Lynch, M. E.; Blinn, K.; Alamgir, F. M.; Choi, Y. Rational SOFC Material Design: New Advances and Tools. Materials Today 2011, 14, 534-546.

(3) Aguadero, A.; Fawcett, L.; Taub, S.; Woolley, R.; Wu, K.; Xu, N.; Kilner, J. A.; Skinner, S. J. Materials Development for IntermediateTemperature Solid Oxide Electrochemical Devices. J. Mater. Sci. 2012, 47, 3925-3948.

(4) Simner, S. P.; Anderson, M. D.; Engelhard, M. H.; Stevenson, J. W.

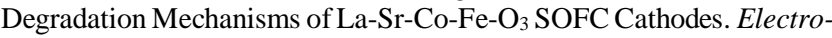
chem. Solid St. 2006, 9, A478-A481.

(5) Jiang, S. P. A Comparison of $\mathrm{O}_{2}$ Reduction Reactions on Porous $(\mathrm{La}, \mathrm{Sr}) \mathrm{MnO}_{3}$ and $(\mathrm{La}, \mathrm{Sr})(\mathrm{Co}, \mathrm{Fe}) \mathrm{O}_{3}$ Electrodes. Solid State Ionics 2002, 146, 1-22.

(6) Endler-Schuck, C.; Joos, J.; Niedrig, C.; Weber, A.; Ivers-Tiffée, E. The Chemical Oxygen Surface Exchange and Bulk Diffusion Coefficient Determined by Impedance Spectroscopy of Porous $\mathrm{La} 0.58 \mathrm{Sr}_{0.4} \mathrm{Co}_{0.2} \mathrm{Fe}_{0.8} \mathrm{O}_{3-\delta}$ (LSCF) Cathodes. Solid State Ionics 2015, 269 , 67-79.

(7) Hu, B.; Guo, K.; Li, M.; Li, Y.; Xia, C. Effect of SDC Grain Size on the Oxygen Incorporation at the LSCF-SDC-Gas Three-Phases Boundary. J. Electrochem. Soc. 2016, 163, F190-F195.

(8) Tietz, F.; Haanappel, V. A. C.; Mai, A.; Mertens, J. Stöver, D. Performance of LSCF Cathodes in Cell Tests. J. Power Sources 2006, 156, 20-22.

(9) Leonide, A.; Rüger, B.; Weber, A.; Meulenberg, W. A.; IversTiffée, E. Impedance Study of Alternative $(\mathrm{La}, \mathrm{Sr}) \mathrm{FeO}_{3-\delta}$ and $(\mathrm{La}, \mathrm{Sr})(\mathrm{Co}, \mathrm{Fe}) \mathrm{O}_{3-\delta} \mathrm{MIEC}$ Cathode Compositions. J. Electrochem. Soc. 2010, 157, B234-B239.

(10) Ritzmann, A. M.; Dieterich, J. M.; Carter, E. A. Density Functional Theory $+\mathrm{U}$ Analysis of the Electronic Structure and Defect Chemistry of LSCF $\left(\mathrm{La}_{0.5} \mathrm{Sr}_{0.5} \mathrm{Co}_{0.25} \mathrm{Fe}_{0.75} \mathrm{O}_{3-\delta}\right)$. Phys. Chem. Chem. Phys. 2016, 18, 12260-12269.

(11) Mastrikov, Y. A.; Merkle, R.; Kotomin, E. A.; Kuklja, M. M.; Maier, J. Formation and Migration of Oxygen Vacancies in La ${ }_{x} \mathrm{Sr}_{\mathrm{x}} \mathrm{Co}_{1-\mathrm{y}} \mathrm{Fe}_{\mathrm{y}} \mathrm{O}_{3-\delta}$ Perovskites: Insight from $a b$ initio Calculations and Comparison with $\mathrm{Ba}_{1-\mathrm{x}} \mathrm{Sr}_{\mathrm{x}} \mathrm{Co}_{1-\mathrm{y}} \mathrm{Fe}_{\mathrm{y}} \mathrm{O}_{3-\delta .}$. Phys. Chem. Chem. Phys. 2013, 15, 911-918.

(12) Mastrikov, Y. A.; Guo, S.; Puleo, F.; Liotta, L. F.; Kotomin, E. A. First Principles Modelling of Pd-Doped $(\mathrm{La}, \mathrm{Sr})(\mathrm{Co}, \mathrm{Fe}) \mathrm{O}_{3}$ Complex Perovskites. Fuel Cells 2016, 16, 267-271.

(13) Gryaznov, D.; Finnis, M. W.; Evarestov, R. A.; Maier, J. Oxygen Vacancy Formation Energies in Sr-Doped Complex Perovskites: $a b$ initio Thermodynamic Study. Solid State Ionics 2012, 254, 11-16. 
(14) Dalslet, B. T.; Sogaard, M.; Hendriksen, P. V. Defect Chemistry and Oxygen Transport of $\left(\mathrm{La}_{0.6} \mathrm{Sr}_{0.4-\mathrm{x}} \mathrm{M}_{\mathrm{x}}\right)_{0.99} \mathrm{Co}_{0.2} \mathrm{Fe}_{0.8} \mathrm{O}_{3-\delta}, \mathrm{M}=\mathrm{Ca}(\mathrm{x}=$ $0.05,0.1), \mathrm{Ba}(\mathrm{x}=0.1,0.2), \mathrm{Sr}$, Part 1: Defect Chemistry. Solid State Ionics 2009, 180, 1173-1182.

(15) Dalslet, B. T.; Sogaard, M.; Hendriksen, P. V. Defect Chemistry and Oxygen Transport of $\left(\mathrm{La}_{0.6} \mathrm{Sr}_{0.4-\mathrm{x}} \mathrm{M}_{\mathrm{x}}\right)_{0.99} \mathrm{Co}_{0.2} \mathrm{Fe}_{0.8} \mathrm{O}_{3-\delta}, \mathrm{M}=\mathrm{Ca}(\mathrm{x}=$ $0.05,0.1), \mathrm{Ba}(\mathrm{x}=0.1,0.2), \mathrm{Sr}$, Part 2: Oxygen Transport. Solid State Ionics 2009, 180, 1050-1060.

(16) Kuklja, M. M; Kotomin, E. A.; Merkle, R.; Mastrikov, Y. A.; Maier, J. Combined Theoretical and Experimental Analysis of Processes Determining Cathode Performance in Solid Oxide Fuel Cells. Phys. Chem. Chem. Phys. 2013, 15, 5443-5471.

(17) Mizusaki, J.; Yoshihiro, M.; Yamauchi, S.; Fueki, K. Nonstoichiometry and Defect Structure of the Perovskite-Type Oxides $\mathrm{La}_{1}$ ${ }_{x} \mathrm{Sr}_{\mathrm{x}} \mathrm{FeO}_{3-\delta}$. J. Solid State Chem. 1985, 58, 257-266.

(18) Pushpa, R.; Daniel, D.; Butt, A. P. Electronic Properties of Ca doped $\mathrm{LaFeO}_{3}$ : A First Principles Study. Solid State Ionics, 2013, 249 250, 184-190.

(19) Bidrawn, F.; Lee, S.; Vohs, J. M.; Gorte, R. J. The Effect of Ca, $\mathrm{Sr}$ and $\mathrm{Ba}$ Doping on the Ionic Conductivity and Cathode Performance of $\mathrm{LaFeO}_{3}$. J. Electrochem. Soc. 2008, 155, B660-B665.

(20) Dho, J.; Hur, N. H.; Magnetic and Transport Properties of Lanthanum Perovskites with B-site Half Doping. Solid State Commun. 2006, $138,152-156$

(21) Haron, W.; Thaweechai, T.; Wattanathana, W.; Laobuthee, A.; Manaspiya, H.; Veranitisagul, C.; Koonsaeng, N. Structural Characteristics and Dielectric Properties of $\mathrm{La}_{1-\mathrm{x}} \mathrm{Co}_{x} \mathrm{FeO}_{3}$ and $\mathrm{LaFe}_{1-\mathrm{x}} \mathrm{Co}_{\mathrm{x}} \mathrm{O}_{3} \mathrm{Syn}-$ thesized via Metal Organic Complexes. Energy Procedia 2013, 34, 791-800.

(22) Lakshminarayanan, N.; Kuhn, J. N.; Rykov, S. A.; Millet, J. M.; Ozkan, U. S. Doped $\mathrm{LaFeO}_{3}$ as SOFC Catalysts: Control of Oxygen Mobility and Oxidation Activity. Catal Today 2010, 157, 446-450.

(23) Ortiz-Vitoriano, N.; Ruiz de Larramendi, I.; Gil de Muro, I.: Ruiz de Larramendi, J. I.; Rojo, T. Nanoparticles of $\mathrm{La}_{0.8} \mathrm{Ca}_{0.2} \mathrm{Fe}_{0.8} \mathrm{Ni}_{0.2} \mathrm{O}_{3-\delta}$. Mater. Res. Bull. 2010, 45, 1513-1519.

(24) Coffey, G. W.; Hardy, J. S.; Pederson, L. R.; Rieke, P. C.; Thomsen, E. C.; Oxygen Reduction Activity of Lanthanum Strontium Nickel Ferrite. Electrochem Solid St. 2003, 6, A121-A124.

(25) Zhong, Z.; Chen, K.; Ji, Y.; Yan, Q. Methane Combustion over Bsite Partially Substituted Perovskite-Type $\mathrm{LaFeO}_{3}$ Prepared by Sol-Gel Method. Appl. Catal. A-Gen. 1997, 156, 29-41.

(26) Zhao, K.; He, F.; Huang, Z.; Wei, G.; Zheng, A.; Li, H.; Zhao, Z. Perovskite-Type Oxides $\mathrm{LaFe}_{1-\mathrm{x}} \mathrm{Co}_{\mathrm{x}} \mathrm{O}_{3}$ for Chemical Looping Steam Methane Reforming to Syngas and Hydrogen Co-Production. Appl. Energ. 2016, 168, 193-203.

(27) Idrees, M.; Nadeem, M.; Mehmood, M.; Atif, M.; Chae, K. H.; Hassan, M. M. Impedance Spectroscopic Investigation of Delocalization Effects of Disorder Induced by Ni Doping in $\mathrm{LaFeO}_{3}$. J. Phys. D: Appl. Phys. 2011, 44, 105401.

(28) Huang, K.; Lee, H. Y.; Goodenough, J. B.; Sr- and Ni-Doped La$\mathrm{CoO}_{3}$ and $\mathrm{LaFeO}_{3}$ Perovskites. J. Electrochem. Soc. 1998, 145, 32203227.

(29) Bcausoleil II, G. L.; Price, P.; Thomsen, D.; Punnoose, A.; Ubic, R.; Misture, S.; Butt, D. P. Thermal Expansion of Alkaline-Doped Lanthanum Ferrite Near the Néel Temperature. J. Am. Ceram. Soc. 2014 97, 228-234.

(30) Sora, I. N.; Caronna, T.; Fontana, F.; Fernández, C. J.; Caneschi, A.; Green, M. Crystal Structures and Magnetic Properties of Strontium and Copper Doped Lanthanum Ferrites. J. Solid State Chem. 2012, 191, 33-39.

(31) Ritzmann, A. M.; Muñoz-García, A. B.; Pavone, M.; Keith, J. A.; Carter, E. A. ab initio DFT+U Analysis of Oxygen Vacancy Formation and Migration in $\mathrm{La}_{1-\mathrm{x}} \mathrm{Sr}_{\mathrm{x}} \mathrm{FeO}_{3-\delta}(\mathrm{x}=0,0.25,0.50)$. Chem. Mater. 2013, 25, 3011-3019.

(32) Jones, A.; Islam, M. S. Atomic-scale Insight into $\mathrm{LaFeO}_{3}$ Perovskite: Defect Nanoclusters and Ion Migration. J. Phys. Chem. C 2008 , $112,4455-4462$.

(33) Selbach, S. M.; Tolchard, J. R.; Fossdal, A.; Grande, T. Non-Linear Thermal Evolution of the Crystal Structure and Phase Transition of $\mathrm{LaFeO}_{3}$ Investigated by High Temperature X-ray Diffraction. J. Solid State Chem. 2012, 196, 249-254.
(34) Taylor, F. H.; Buckeridge, J.; Catlow, C. R. A. Defects and Oxide Ion Migration in the Solid Oxide Fuel Cell Cathode Material $\mathrm{LaFeO}_{3}$. Chem. Mater. 2016, 28, 8210-8220.

(35) Hohenberg, P.; Kohn, W. Inhomogeneous Electron Gas. Phys. Rev. 1964, 135, B864-B871.

(36) Kohn, W.; Sham, L. J. Self-Consistent Equations Including Exchange and Correlation Effects. Phys. Rev. 1965, 140, A1133-A1138. (37) Dudarev, S. L.; Botton, G. A.; Savrasov, S. Y.; Humphreys, C. J.; Sutton, A. P. Electron-Energy-Loss Spectra and the Structural Stability of Nickel Oxide: An LSDA+U Study. Phys. Rev. B 1998, 57, 15051509.

(38) Blöchl, P. E. Projector Augmented-Wave Method. Phys. Rev. B 1994, 50, 17953-17979.

(39) Kresse, G.; Hafner, J. Ab initio Molecular Dynamics for OpenShell Transition Metals. Phys. Rev. B 1993, 48, 13115-13118.

(40) Kressee, G.; Furthmüller, J. Efficient Iterative Schemes for $a b$ initio Total-Energy Calculations using a Plane-Wave Basis Set. Phys. Rev. B 1996, 54, 11169-11186.

(41) Kressee, G.; Furthmüller, J. Efficiency of ab-initio Total Energy Calculations for Metal and Semiconductors using a Plane-Wave Basis Set. Comput. Mater. Sci. 1996, 6, 15-50.

(42) Perdew, J. P.; Burke, K.; Ernzerhof, M. Generalized Gradient Approximation made Simple. Phys. Rev. Lett. 1996, 77, 3865-3868.

(43) Monkhorst, H. J.; Pack, J. D. Special Points for Brillouin-Zone Integrations. Phys. Rev. B 1976, 13, 5188-5192.

(44) Buckeridge, J.; Taylor, F.H.; Catlow, C. R. A. Efficient and Accurate Approach to Modelling the Microstructure and Defect Properties of $\mathrm{LaCoO}_{3}$. Phys. Rev. B 2016, 93, 155123.

(45) Marezio, M.; Dernier, P. D. The Bond Lengths in $\mathrm{LaFeO}_{3}$. Mater. Res. Bull. 1971, 6, 23-29.

(46) Arima, T.; Tokura, Y.; Torrance, J. B.; Variation of Optical Gaps in Perovskite-type 3d Transition-Metal Oxides. Phys. Rev. B 1993, 48 , 17006-17009.

(47) Koehler, W. C.; Wollan, E. O. Neutron-Diffraction Study of the Magnetic Properties of Perovskite-like Compounds $\mathrm{LaBO}_{3}$. J. Phys. Chem. Solids 1957, 2, 100-106.

(48) Bhargav, K. K.; Ram, S.; Majumder, S. B. Small Polaron Conduction in Lead Modified Lanthanum Ferrite Ceramics. J. Alloys Compd. 2015, 638, 334-343

(49) Youmbi, B. S.; Calvayrac, F.; Structure of $\mathrm{CoO}$ (001) Surface from DFT+U Calculations. Surf. Sci. 2014, 621, 1-6. (50) Dalverny, A.-L.; Filhol, J.-S.; Lemoigno, F.; Doublet, M.-L.; Interplay between Magnetic and Orbital Ordering in the Strongly Correlated Cobalt Oxide: A DFT+U Study. J. Phys. Chem. C 2010, 114, 21750-21756.

(51) Floris, A.; Gironcoli, S.; Gross, E. K. U.; Cococcioni M.; Vibrational Properties of $\mathrm{MnO}$ and $\mathrm{NiO}$ from $\mathrm{DFT}+\mathrm{U}$-based Density Functional Perturbation Theory. Phys. Rev. B 2011, 84, 161102.

(52) Sebbari, K.; Roques, J.; Domain, C.; Simoni, E.; Uranyl Ion Interaction at the Water $/ \mathrm{NiO}(100)$ interface: A Predictive Investigation by First Principles Molecular Dynamics Simulations. J. Chem. Phys. 2012, 137, 164701 .

(53) Forti, M.; Alonso, P.; Gargano, P.; Rubiolo, G.; Transition Metals Monoxides. An LDS+U Study, Procedia Mater. Sci. 2012, 1, 230-234. (54) Novoselov, D.; Korotin, D. M.; Anisimov, V. I.; Hellmann-Feynman Forces within the DFT+U in Wannier Functions Basis, J. Phys. Condens. Mat. 2015, 27, 325602.

(55) Yang, B.-X.; Ye. Li.-P.; Gu, H. -J.; Huang J. -H.; Li, H. -Y.; Luo, Y.; A Density Functional Theory Study of $\mathrm{CO}$ Oxidation on $\mathrm{CuO}_{1}$. x(111). J. Mol. Model 2015, 21, 10.1007/s00894-015-2726-x.

(56) Ekuma, C. E.; Anisimov, A. I.; Moreno, J.; Jarrell, M.; Electronic Structure and Spectra of CuO. Eur. Phys. J. B 2014, 87, 10.1140/epjb/e2013-40949-5.

(57) Yang, Z.; Wang, Q.; Wei, S.; The Synergistic Effects of the Cu$\mathrm{VeO}_{2}$ (111) Catalysts on the Adsorption and Dissociation of Water Molecules. Phys. Chem. Chem. Phys. 2011, 13, 9363-9373.

(58) Nolan, M.; Elliott, S. D.; The p-type Conduction Mechanism in $\mathrm{Cu}_{2} \mathrm{O}$ : A First Principles Study. Phys. Chem. Chem. Phys. 2006, 8, 5350-5358.

(59) Kanan, D. K.; Keith, J. A.; Carter, E. A.; Water Adsorption on $\mathrm{MnO}: \mathrm{ZnO}(001)$ - From single molecules to bilayer coverage. Surf. Sci. 2013, 617, 218-224. 
(60) Toroker, M. C.; Carter, E. A.; Transition Metal Oxide Alloys as Potential Solar Energy Conversion Materials. J. Mater. Chem. A 2013 , $1,2474-2484$

(61) Lany, S.; Zunger, A. Assessment of Correction Methods for the Band-Gap Problem and for the Finite-size Effects in Supercell Defect Calculations: Case studies for $\mathrm{ZnO}$ and GaAs. Phys. Rev. B 2008, 78 , 235104

(62) Murphy, A. T.; Hine, N. D. M. Anisotropic Charge Screening and Supercell Size Convergence of Defect Formation Energies. Phys. Rev. B 2013, 87, 094111.

(63) Kroger, A. F. The Chemistry of Imperfect Crystals: Imperfection Chemistry of Crystalline Solids; North-Holland Pub. Co.: Amsterdam, 1974.

(64) Grau-Crespo, R.; Hamad, S.; Catlow, C. R. A.; Leeuw, N.H. Symmetry-Adapted Configurational Modelling of Fractional Site Occupancy in Solids. J. Phys.: Condens. Matter 2007, 19, 256201.

(65) Cherry, M.; Islam, M. S.; Catlow, C. R. A. Oxygen Ion Migration in Perovskite-Type Oxides. J. Solid State Chem. 1995, 118, 125-130.

(66) Lewis, G. V.; Catlow, C. R. A. Potential Models for Ionic Oxides. J. Phys. C Solid State Phys. 1985, 18 1149-1161.

(67) Islam, M. S.; Winch, L. J. Defect Chemistry and Oxygen Diffusion in the $\mathrm{HgBa}_{2} \mathrm{Ca}_{2} \mathrm{Cu}_{3} \mathrm{O}_{3+\delta}$ Superconductor: A Computer Simulation Study. Phys Rev B 1995, 52, 10510-10515.

(68) Gale, J. D.; Rohl, A. L. The General Utility Lattice Program (GULP). Mol. Simul. 2003, 29, 291-341.

(69) Sasaki, S.; Fujino, K.; Takéuchi, Y. X-Ray Determination of Electron-Density Distributions in Oxides, $\mathrm{MgO}, \mathrm{MnO}, \mathrm{CoO}$ and $\mathrm{NiO}$, and Atomic Scattering Factors of their Constituent Atoms. Proc. Japan Acad. 1979, 55, 43-48.

(70) Smith, D. K. Jr; Leider, H. R. Low-Temperature Thermal Expansion of $\mathrm{LiH}, \mathrm{MgO}$ and CaO. J. Appl. Crystallogr. 1968, 1, 246-249.

(71) Taylor, D. Thermal Expansion Data: I. Binary Oxides with the Sodium Chloride and Wurtzite Stucture, MO. Brit. Ceram. Trans. J. 1984, $83,5-9$.

(72) Lingun, L.; Bassett, W. A. Effect of Pressure on the Crystal Structure and Lattice Parameters of BaO. J. Geophys. Res. 1972, 77, 49344937.

(73) Brese, N. E.; O’Keeffe, M.; Ramakrishna, B. L.; von Dreele, R. B. Low-Temperature Structures of $\mathrm{CuO}$ and $\mathrm{AgO}$ and their relationships to those of $\mathrm{MgO}$ and PdO. J. Solid State Chem. 1990, 89, 184-190.

(74) Carter, R. E.; Richardson, F. D. Oxidation of Cobalt Metal. J. Met. 1955, 7, 336-343.

(75) Fjellvag, H.; Gronvold, F.; Stolen, S.; Hauback, B. C. On the Crystallographic and Magnetic Structures of Nearly Stoichiometric Iron Monoxide. J. Solid State Chem. 1996, 124, 52-57.

(76) Shannon, R. D. Revised Effective Ionic Radii and Systematic Studies of Interatomic Distances in Halides and Chalcogenides. Acta Cryst. 1976, A32, 751-767.

(77) Lewis, G. V.; Catlow, C. R. A.; Defect Studies of Doped and Undoped Barium Titanate using Computer Simulation Techniques. J. Phys. Chem. Solids 1986, 47, 89-97.
(78) Patrakeev, M. V.; Bahteeva, J. A.; Mitberg, E. B.; Leonidov, I. A.; Kozhevnikov, V. L.; Poeppelmeier, K. R. Electron/Hole and Ion Transport in $\mathrm{La}_{1-\mathrm{x}} \mathrm{Sr}_{\mathrm{x}} \mathrm{FeO}_{3-\delta}$. J. Solid State Chem. 2003, 172, $219-231$. (79) Ghosh, S.; Dasgupta, S. Synthesis, Characterization and Properties of Nanocrystalline Perovskite Cathode Materials. Mater. Sci. -Pol. 2010, 28, 427-438.

(80) Andoulsi, R.; Horchani-Naifer, K.; Férid, M. Structural and Electrical Properties of Calcium Substituted Lanthanum Ferrite Powders. Powder Technol. 2012, 230, 183-187.

(81) Hassan, M. S.; Shim, K. B.; Yang, O. B. Electrocatalytic Behaviour of Calcium Doped $\mathrm{LaFeO}_{3}$ as Cathode Material for Solid Oxide Fuel Cell. J. Nanosci. Nanotechnol. 2011, 11, 1429-1433.

(82) Küngas, R.; Yu, A. S.; Levine, J.; Vohs, J. M.; Gorte, R. J. An Investigation of Oxygen Reduction Kinetics in LSF Electrodes. J. Electrochem. Soc. 2013, 160, F205-F211.

(83) Timurkutluk B.; Timurkutluk C.; Mat, M. D.; Kaplan, Y. Development of High-Performance Anode Supported Solid Oxide Fuel Cell. Int. J. Energ. Res. 2012, 36, 1383-1387.

(84) Goldschmidt, V. M. Die Gesetze der Krystallochemie, Naturwissenschaften 1926, 14, 477-485.

(85) Liu, S.; Liu, Q.; Luo, J. The Excellence of $\mathrm{La}(\mathrm{Sr}) \mathrm{Fe}(\mathrm{Ni}) \mathrm{O} 3$ as an Active and Efficient Cathode for Direct $\mathrm{CO}_{2}$ Electrochemical Reduction at Elevated Temperature. J. Mater. Chem. A 2017, 2673-2680.

(86) Zhu, G.; Fang, X.; Xia, C.; Liu, X. Preparation and Electrical Properties of $\mathrm{La}_{0.4} \mathrm{Sr}_{0.6} \mathrm{Ni}_{0.2} \mathrm{Fe}_{0.8} \mathrm{O}_{3}$ using a Glycine Nitrate Process. Ceram. Int. 2005, 31, 115-119.

(87) Chiba, R.; Yoshimura, F.; Sakurai, Y. An Investigation of LaNi ${ }_{1-}$ ${ }_{x} \mathrm{Fe}_{\mathrm{x}} \mathrm{O}_{3}$ as a Cathode Material for Solid Oxide Fuel Cells. Solids State Ionics 1999, 124, 281-288.

(88) Kharton, V. V.; Viskup, A. P.; Naumovich, E. N.; Tikhonovich, V. N. Oxygen Permeability of $\mathrm{LaFe}_{1-\mathrm{x}} \mathrm{Ni}_{\mathrm{x}} \mathrm{O}_{3-\delta}$ Solid Solutions. Mater. Res. Bull. 1999, 34, 1311-1317.

(89) Díez-García, M. I.; Gómez, R. Metal Doping for Enhancing the Photoelectrochemical Behaviour of $\mathrm{LaFeO}_{3}$ Photocathodes. ChemSusChem 2017, 10.1002/cssc.201700166.

(90) Kuhn, M.; Hashimoto, S.; Sato, K.; Yashiro, K.; Mizusaki, J. Thermo-Chemical Lattice Expansion in $\mathrm{La}_{0.6} \mathrm{Sr}_{0.4} \mathrm{Co}_{1-\mathrm{y}} \mathrm{Fe}_{\mathrm{y}} \mathrm{O}_{3-\delta}$. Solid State Ionics 2013, 241, 12-16.

(91) Sereda, V. V.; Tsvetkov, D. S.; Ivanov, I. L.; Zuev, A. Y. Oxygen Nonstoichiometry, Defect Structure and Related Properties of $\mathrm{LaNi}_{0.6} \mathrm{Fe}_{0.4} \mathrm{O}_{3-\delta}$. J. Mater. Chem. A 2015, 3, 6028-6037.

(92) Niwa, E.; Hashimoto, T.; Dependence of Thermal Expansion of $\mathrm{LaNi}_{0.6} \mathrm{Fe}_{0.4} \mathrm{O}_{3-\delta}$ and $\mathrm{La}_{0.6} \mathrm{Sr}_{0.4} \mathrm{Co}_{0.2} \mathrm{Fe}_{0.8} \mathrm{O}_{3-\delta}$ on Oxygen Partial Pressure. Solid State Ionics 2016, 285, 187-194.

(93) Gan, L.; Zhong, Q.; Zhao, X.; Song, Y.; Bu, Y. Structural and Electrochemical Properties of B-site Mg-Doped La0.7 $\mathrm{Sr}_{0.3} \mathrm{MnO}_{3-\delta}$ Perovskite Cathodes for Intermediate Temperature Solid Oxide Fuel Cells. J. Alloys Compd. 2016, 655, 99-105.

(94) Wei, Z-X.; Wang, Y.; Liu, J-P.; Xiao, C-M.; Zeng, W-W.; Ye, SB. Synthesis, Magnetization, and Photocatalytic Activity of $\mathrm{LaFeO}_{3}$ and $\mathrm{LaFe}_{0.9} \mathrm{Mn}_{0.1} \mathrm{O}_{3-\delta .}$. J. Mater. Sci. 2013, 48, 1117-1126.

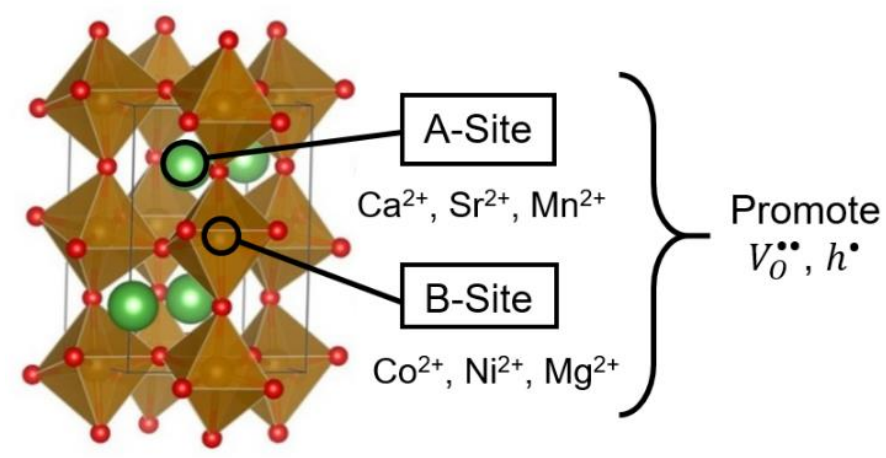


